\title{
Wide Hybridization and Embryo-Rescue for Crop Improvement in Capsicum
}

\author{
C Debbarama, VK Khanna, W Tyagi, M Rai and NT Meetei
}

College of Post-Graduate Studies, CAU, Umiam-793103, Meghalaya, India

\begin{abstract}
Wide-hybridization is an important tool in the hands of the plant breeder and a cytogeneticist. It is the first step to transfer genes of the wild species into the cultivated ones. In Meghalaya, chilli is the third most important spice crop after ginger and turmeric. However, diseases namely, tobacco mosaic virus, root rot, tomato spotted wilt virus, etc. lead to a considerable decline in yield. Capsicum chinense, $C$. annuum and $C$. frutescens were crossed with each other and embryo rescue was done between 27-33 days after pollination. The highest percentage of embryo growth was observed in MS medium with $0.5 \mathrm{mg} / \mathrm{l} \mathrm{GA}$ and $0.05 \mathrm{mg} / \mathrm{l} \mathrm{NAA}$. Hybrid plants were obtained and their hybridity was confirmed using both morphological and RAPD markers.
\end{abstract}

Keywords: Interspecific-hybridization; Capsicum species; Embryorescue; RAPD

\section{Introduction}

North-East India is one of the 12 mega bio-diversity hot spots in the world [1]. In vegetables at least 12 species of Solanum are consumed by the local people. Many wild relatives can also contribute as donors in the hybridization programme. Enormous diversities exist within Capsicum at the interspecific level and also in their landraces. Wide hybridization is an important tool in the hands of the plant breeder and a cytogeneticist. It is the first step to transfer desirable traits from one species into another.

Successful sexual hybridization involves a series of events including pollen germination, pollen tube growth, fertilization, embryo and endosperm development, and seed maturation. Stebbins [2] divided hybridization barriers into two broad groups, namely pre-fertilization and post-fertilization barriers. The pre-fertilization category includes those mechanisms which prevent fertilization and includes geographical isolation, apomixes, and pollen-pistil incompatibilities. Post-fertilization barriers are a greater hindrance to hybridization and can be a result of ploidy differences, chromosome elimination, seed dormancy and hybrid breakdown of particular importance is the need to get hybrids that are fertile.

To bypass pre-zygotic barriers, the following can be done [3] Where premature flower abscission takes place, hormone application may prolong the life of the flower. To increase pollen germination, one can apply boric acid, sucrose or abstract of the compatible anthers. We can amputate the stigma and apply sucrose-gelatin paste. One can apply self and other species pollen or bud pollination can be tried. To speed up pollen tube growth, application of growth regulators e.g., IAA, 2,4-D or $\mathrm{GA}_{3}$ or use of radiation or an immunosuppressant like alphaamino caproic acid as in Vigna radiate x Vigna umbellate can help. If there is stylar incompatibility, then one can shorten the style as in maize into Tripsacum cross or we can manipulate the ploidy levels of the parents. The use of intra-ovarian pollination has also been used to effect pollination by bypassing the style. This technique which involves injecting a suspension of pollen grains directly into the ovary was used with Papaver somniferum to produce normal fruits in vivo which contained viable seeds.

To bypass post-fertilization barriers, embryo-rescue, ovule culture and manipulations with protoplasts have been successfully used.

\section{Interspecific hybridization and embryo rescue in Capsicum}

Chilli belongs to the genus Capsicum, which is among the world's extensively grown spice crops. India ranks first with an average yield of $1.6 \mathrm{mt} \mathrm{ha}^{-1}$ from the total cultivated area of 7.67 lakhs ha. In Meghalaya, it is the third most important spice crops after ginger and turmeric with an area of 1900 hectares and a production of 2300 tones. However, diseases namely, Tobacco Mosaic Virus (TMV), root rot, Tomato Spotted Wilt Virus (TSWV), etc. leads to a considerable decline in yield. It is therefore necessary to transfer the important genes for various characters from one species to another. But there has been very little success due to problems in crossability. According to Shoemaker [4], in Capsicum annuum x C. frutescens, in general about two per cent seeds were viable when $C$. frutescens was used as the female parent. The $\mathrm{F}_{1}$ plants ranged from completely pollen sterile to pollen fertile. In $C$. annuum $\mathrm{x} C$. chinense crosses are much easier when $C$. annuum is used as the female parent. Only an occasional successful cross was obtained in the other direction. The $\mathrm{F}_{1}$ were mostly pollen sterile. Similar results were obtained in the crosses between $C$. frutescens and $C$. chinense. The TMV genes have been transferred from $C$. chinensis to $C$. annuum. Resistance for fruit rot of chilli pepper caused by anthracnose was identified in C. baccatum and C. annuum by Pae et al. [5] but unfortunately, these species cannot be crossed easily. C. chinense, $C$. baccatum, C. frutescens and C. pubescence are used as genetic resources for disease resistance genes [6].

The present investigation was carried out on three species viz., Capsicum annuum, Capsicum chinense, and Capsicum frutescens, to determine whether this low success in crossability is due to prefertilization problems and to find out the optimum timing for embryo rescue. Hybrid plants were obtained and their hybridity was confirmed using both morphological and molecular markers (RAPD).

*Corresponding author: V. K. Khanna, College of Post-Graduate Studies, CAU, Umia793103, Meghalaya, India, E-mail:khannavk@rediff.com

Received December 06, 2012; Accepted December 25, 2012; Published December 31, 2012

Citation: Debbarama C, Khanna VK, Tyagi W, Rai M, Meetei NT (2013) Wide Hybridization and Embryo-Rescue for Crop Improvement in Capsicum. Agrotechnol S11: 003. doi:10.4172/2168-9881.S11-003

Copyright: (C) 2013 Debbarama C, et al. This is an open-access article distributed under the terms of the Creative Commons Attribution License, which permits unrestricted use, distribution, and reproduction in any medium, provided the original author and source are credited. 


\section{Material and Methods}

The experimental material used in the present study comprised of three species including two varieties and two accessions of Chilli, respectively i.e. Capsicum annuum namely Kashi Anmol and Pusa jwala and C. chinense (COO-304) and C. frutescence (COO-904).

Experimental strategies were developed by adopting various standard and self developed techniques. They were suitably modified as per the need of the experiment. The complete course of the investigations was divided into the following parts.

\section{A. Crossability studies}

1. Selfing and inter-specific crosses

2. Pollen viability, pollen germination, pollen tube growth and fruit set.

\section{B. Correlation studies for various characters in inter-specific crosses of Capsicum}

\section{In vitro studies: embryo rescue}

1. Effect of the age of the hybrid embryos, on development, when cultured on media

2. Effect of media

\section{Confirmation of hybridity by morphological and molecular markers}

\section{Results and Discussion}

\section{Viable pollen}

The average percentage of viable pollen showed little differences among the different species (Figure 1). There seems to be no correlation between viable pollen with the fruit set. Pollen adhesion on the stigmatic surface involves both impaction and the subsequent formation of attachment bonds [7]. According to Clarke et al. [8] on initial contact, the adhesive components could be contributed by either or both the partners, to enhance mutual adhesion. The specificity needed for foreign pollen discrimination might be provided by adhesive base or the thickening agents, both high molecular weight components (protein and carbohydrates) (Figure1).

\section{Pollen germination}

In the present study there was regular increase in percent pollen germination after 10 hours, 20 hours and 30 hours in both selfing and in reciprocal crosses. After 30 hours pollen germination was more in

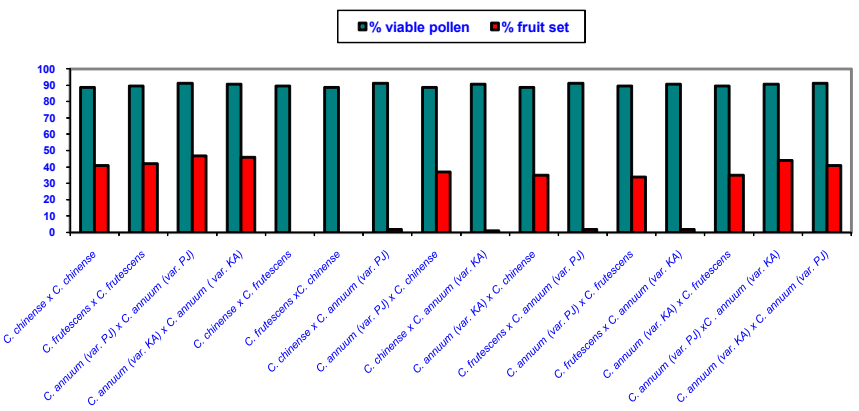

Figure 1: Percent viable pollen and percent fruit set on selfing and reciprocal crosses in different species of Capsicum.

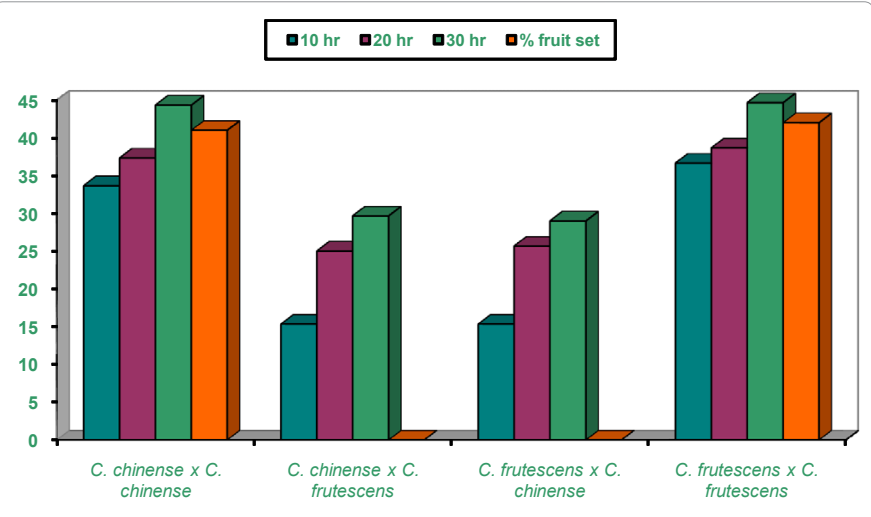

Figure 2: Pollen germination at different time intervals in selfing and in reciprocal crosses of $C$. chinense (COO-304) and C. frutescens (COO-904) and percent fruit set.

selfings than in crosses (Figure 2). Percent pollen germination after 30 hours of pollination showed significant positive correlation with fruit set. When C. annuum was used as the female, higher percent fruit set was recorded than in $C$. frutescence and $C$. Chinense where the fruit set was exceptionally as low as 1-2 percent.

Rehydration of mature pollen grains is an essential prelude to germination [6]. Since the water potential of the dry grain is lower than that of the stigma surfaces, it is readily apparent that the water of hydration will move in the direction of decreasing water potential from the stigma cell to the pollen grain. In a natural pollination, hydration is from a dry stigma. The water uptake, although rapid, is thus controlled and probably self regulatory $[9,10]$. Unregulated hydration leads to the bursting of the grain However, tube growth in the secondary stigma branch is accompanied by shrinkage of hydrated grain, indicating that water is abstracted from the grain during the early extension. This conclusion provides the explanation that when there is competition between tubes some may fail to enter and will then continue growth on the surface of the branch or even in the air [11]. The rapid transition of the male gametophyte state of comparative inactivity in the grain to vigorous growth for the germination of pollen implies rapid reestablishment of a normal metabolism, including notably the synthetic capacity required for the synthesis of the pollen tube wall. The activation of pollen grain depends on rehydration which depends on the inflow of water from the stigma after attachment of the grain. Hydration in the suitable medium leads to the extrusion of the intine of the aperture [10]. In the viable grains azonation is quickly developed, generally within 5 minutes from the beginning of hydration (Figure 2).

\section{Pollen tube growth}

Pollen tube growth increased with the passage of time (Figure 3). At 10 hours of pollination a number of pollen grains had germinated and the tubes had penetrated into the stigma hairs. Some of the pollen tubes had just started their growth in the hairs and a few had already entered the transmitting tissue of the style. After 20 hours of pollination there was a greater differentiation and elongation in the pollen tubes whereas some had just started to elongate and all intermediate stages were observed. After 30 hours of pollination, very long pollen tubes were recorded and since the styles were quite long, the pollen tubes could not be traced up to the base of the style as their staining became faint as they worked their way towards the ovary (Figure 3).

Fruit set showed a highly significant positive correlation with pollen tube growth (0.885) (Table 1). 


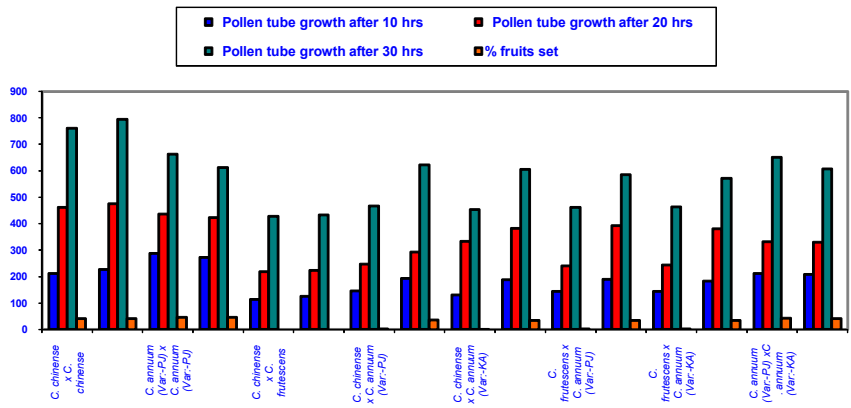

Figure 3: Pollen tube growth at different time intervals and percent fruit set.

\begin{tabular}{|l|l|l|l|}
\hline Characters & $\begin{array}{l}\text { Pollen tube } \\
\text { growth }\end{array}$ & $\begin{array}{l}\text { Percent viable } \\
\text { pollen }\end{array}$ & Percent fruit set \\
\hline Percent pollen germination & 0.102 & 0.754 & $0.956^{\star *}$ \\
\hline Pollen tube growth & - & 0.786 & $0.885^{\star}$ \\
\hline Percent viable pollen & - & - & -0.119 \\
\hline Percent fruit set & & & \\
\hline
\end{tabular}

** Significant at 0.01 probability level

* Significant at 0.05 probability level

Table 1: Correlation studies for various characters in inter-specific crosses of Capsicum.

\section{Fruit set}

A good fruit set was recorded in the case of selfing in Capsicum chinense, COO-304, Capsicum frutescence, COO-904, Capsicum annuum, variety Pusa jwala and Capsicum annuum, variety Kashi Anmol. Within selfing, Capsicum annuum variety Pusa jwala showed a high fruit set (47 percent). High pollen germination was also recorded on selfing of Capsicum annuum, variety Pusa jwala (Figure 2). Among the inter-specific crosses Capsicum annuum, variety Pusa jwala $\mathrm{X}$ Capsicum chinense, COO-304 showed maximum fruit set (37 percent) i.e. again when Capsicum annuum, variety Pusa jwala was used as the female parent. In this cross, pollen germination was comparable, and pollen viability also higher. Crossing in Capsicum annuum with Capsicum chinense and Capsicum frutescence was much easier when $C$. annuum was used as the female parent and between C. chinense and $C$. frutescens there was no success which was also reported by Shoemaker [3].

However, fruit set in chilli is a varietal characteristic that depends to a large extent on environmental conditions. Low fruit set is one of the constraints to higher yields of chilli in the tropics [12]. Also, there was a significant link between plant height and fruit number in other pepper cultivar types. The fruit yield reduction in Solanaceous crops was observed due to high temperatures [13]. Successful fruit set depends on several reproductive processes including pollen germination and tube growth processes.

\section{Relationship of different parameters with fruit set}

Number of fruits formed had a negative but non-significant correlation with percent viable pollen $(-0.119)$ while fruit set showed a highly significant positive correlation with percent pollen germination (0.956) and pollen tube growth (0.885). Percent viable pollen and percent pollen germination showed positive relationship with percent fruit set for the reciprocal crosses and on selfing of different species of Capsicum. The exceptional case was of crosses when Capsicum chinense, COO-304 and Capsicum frutescence, COO-904 were used as the female parent, where percent pollen germination and viable pollen was average, still a low fruit set was observed. This may be due to some post-fertilization incompatibility.

\section{Correlation studies}

Correlation studies between various pre-fertilization and postfertilization factors showed that fruit set showed a highly significant positive correlation with percent pollen germination and pollen tube growth (Table 1). It showed that the high percent of pollen germination and pollen tube growth increases the fruit formation. On the other hand, fruit formation frequency was found negatively correlated with percent viable pollen. Positive correlation has been reported between pollen tube length and seed set in wheat $\mathrm{x}$ barley crosses [14].

\section{Embryo rescue}

In in vitro studies, plant regeneration was achieved via somatic embryogenesis. The percentage of regenerating culture was optimized in the explants by supplying appropriate amounts of the hormone, exogenously in the medium.

In the present study, embryo rescue technique was applied by using MS (1962) modified medium. The embryos obtained from young immature fruits ranging from 27-36 days after pollination were cultured on various modifications of MS medium supplemented with growth hormones. It was observed that the stage of development of the hybrid embryos at the time of culture was of the utmost importance; and their growth was strongly influenced by their age (Table 2). The success of embryo rescue in wide crosses is influenced by the age of the embryo at the time of its culture. The two stages of embryo growth exist with regard to nutritional independence [15]. The heterotrophic stage of growth is the period during which the embryo depends on the endosperm for its nutrition; it extends from the fertilization to approximately the heart stage. The autotrophic phase starts from the late heart stage. This stage is significant for the in vitro culture as the embryo becomes sufficiently independent of the endosperm for the subsequent growth. Once the abortion process began, they were difficult to grow. The younger embryos (22-25 DAP) were very difficult to excise and had a tendency to stop growing after an initial increase in size or they gave rise to weak, lean and abnormal looking plantlets. The older embryos (35-36 DAP) started shriveling and showing sign of degeneration because the process of abortion had already set in. Such embryos in culture either died or produced callus with malformed plants. As can be seen from table 2, the best growth was obtained from 27-33 DAP embryos.

The normal development of the embryos was realized on a basal medium supplemented with NAA @ 0.05mg/l and GA @ 0.5 mg/l. The addition of Casein hydrolysate and Yeast extract showed the highest percent of embryo growth (Table 3).

The result conforms to the work done by Hossain et al. [15] according to whom the age of the explants 28-33 DAP and GA @ 0.5 mg/l and NAA@0.05 mg/l showed good results. The breeding barriers in interspecific in interspecific hybrids of tomato have been overcome using two given methods [16]. Firstly, hybrid embryos have been rescued

\begin{tabular}{|c|c|c|}
\hline SI. No. & $\begin{array}{c}\text { Age of the embryo } \\
\text { (days after pollination) }\end{array}$ & Growth response \\
\hline 1 & $22-25$ & Extremely small, difficult to excise \\
\hline 2 & $27-33$ & Healthy plantlets, showing growth \\
\hline 3 & $35-36$ & $\begin{array}{c}\text { Some grew and produced plantlets, in others } \\
\text { where embryos already started showing sign } \\
\text { of degeneration, die in culture }\end{array}$ \\
\hline
\end{tabular}

Table 2: Effect of the age of the hybrid embryos, on development, when cultured on media. 
Citation: ' HEEDIDP DI\&WKhanna VK, Tyagi W, Rai M, Meetei NT (2013) Wide Hybridization and Embryo-Rescue for Crop Improvement in Capsicum. Agrotechnol S11:003. doi:10.4172/2168-9881.S11-003

Page 4 of 6

\begin{tabular}{|l|c|c|c|c|c|c|c|}
\hline Media & $\begin{array}{c}\text { Casein } \\
\text { hydroly-sate } \\
\text { (mg/l) }\end{array}$ & $\begin{array}{c}\text { Yeast } \\
\text { extract } \\
\text { (mg/l) }\end{array}$ & $\begin{array}{c}\text { GA3 } \\
\text { (mg/l) }\end{array}$ & $\begin{array}{c}\text { NAA } \\
\text { (mg/l) }\end{array}$ & $\begin{array}{c}\text { Number of } \\
\text { embryos } \\
\text { cultured }\end{array}$ & $\begin{array}{c}\text { Number of } \\
\text { embryos } \\
\text { showing } \\
\text { growth }\end{array}$ & $\begin{array}{c}\text { Embryos } \\
\text { showing } \\
\text { growth (\%) }\end{array}$ \\
\hline MS-1 & 500 & 500 & 0.25 & 0.025 & 20 & 0.0 & 0.0 \\
\hline MS-2 & 500 & 500 & 0.25 & 0.050 & 20 & 0.0 & 0.0 \\
\hline MS-3 & 500 & 500 & 0.25 & 0.100 & 20 & 0.0 & 0.0 \\
\hline MS-4 & 500 & 500 & 0.50 & 0.025 & 20 & 2.0 & 10.0 \\
\hline MS-5 & 500 & 500 & 0.50 & 0.050 & 20 & 16.0 & 84.0 \\
\hline MS-6 & 500 & 500 & 0.50 & 0.100 & 20 & 3.0 & 15.0 \\
\hline MS-7 & 500 & 500 & 0.75 & 0.025 & 20 & 0.0 & 0.0 \\
\hline MS-8 & 500 & 500 & 0.75 & 0.050 & 20 & 0.0 & 0.0 \\
\hline MS-9 & 500 & 500 & 0.75 & 0.100 & 20 & 0.0 & 0.0 \\
\hline
\end{tabular}

i. MS- 1, 2, 3, 7, 8 and 9 not showing any signs of embryo formation.

ii. MS- 4 and 6 shows embryo formation but growth inhibited/growth improved occasional sparse proliferation.

iii. MS- 5 showed healthy plantlets; frequent formation of multiple roots (plate $2,3,4,5,6)$.

Table 3: Effect of media composition on embryo formation.

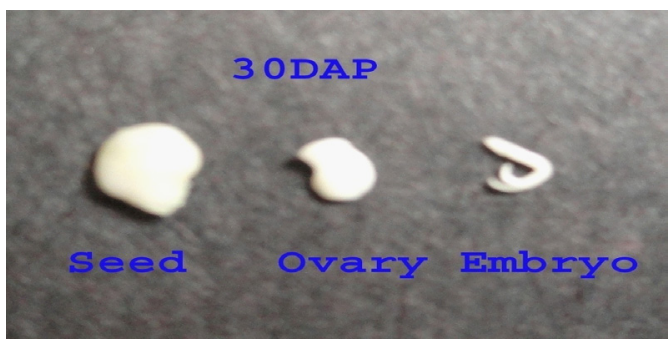

Plate 1: Immature seed, ovary and embryo 30 days after pollination in $C$. chinense $\times$ C. annuum (Kashi Anmol).

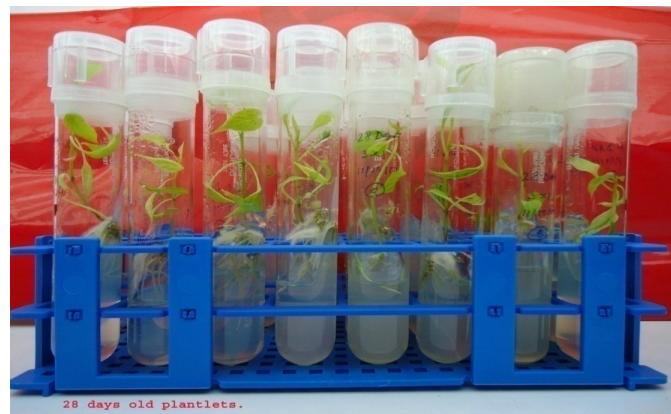

Plate 2: 28 days old plantlets of $C$. chinense x C. annuum (Kashi Anmol) after embryo rescue in culture tube.

by embryo culture [17], ovule culture [18] and plant regeneration from ovule-derived callus [19]. Secondly, normal seed development has been obtained by adjusting the environment and crossing factors during the crossing period and fruit growth [20], pollination with gamma-ray irradiated pollen grains [21], use of polyploidy [22], bridge crossing [23] and the selection of self-compatible species [24]. However, the plants obtained are very few (plate 1) (Table 2).

\section{Hybridity test by morphological markers}

When the morphological parameters of the parents and the hybrids were compared, it was seen that there were clear cut differences in the height or fruit shape (Plates 2-6) of the hybrids as compared to the parents. The method of hybrid identification based on morphological characters can be used but these are influenced by environmental factors and frequently lack the resolving power to identify hybrids at the juvenile stages, so one has to wait for the plants to reach maturity.

\section{Hybridity Test by RAPD markers}

A total of 810 -mer primers were used to screen polymorphism between the two pairs of parents. Out of the primers tested, all 8 produced clear amplification products. On an average each primer amplified 6.62 scorable bands (Table 4). To test the conformity of hybrid progeny, one must be able to distinguish, within a random sample of plants, those resulting from crossing the female and male parents obtained through embryo rescue. To check both possibilities with our markers, a first selection was done among the 8 clear primers and 16 (30.2\%) showed polymorphism between the parents. Data on those 8 primers were used to select further for the presence of bands specific to the male parent of each hybrid. Only those primers which amplified bands specific to the male parent might reveal a proper pattern of a true hybrid as opposed to that of a selfed seed of the female parent. In the latter case, the band pattern would reflect the absence of the male band and the presence

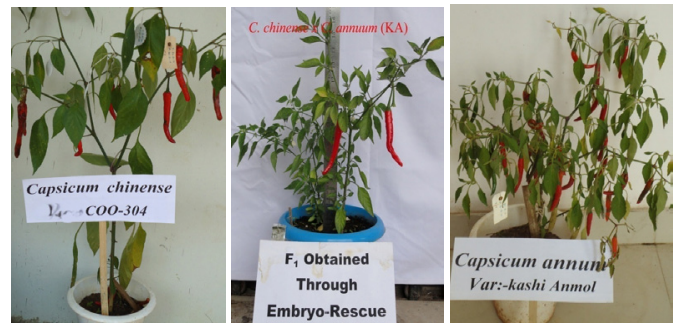

Plate 3: $F_{1}$ of $C$. chinense $\times C$. annuum (Kashi Anmol) obtained through embryo rescue.
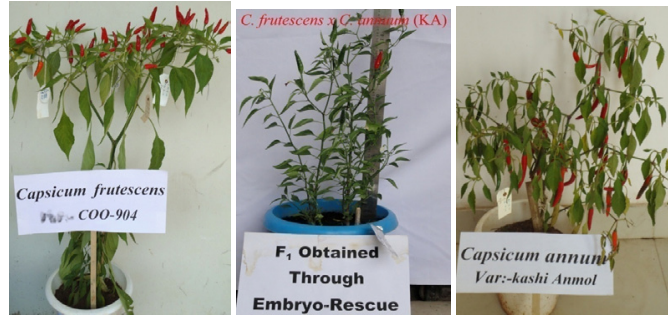

Plate 4: $F_{1}$ of $C$. frutescence $\times C$. annuum (Kashi Anmol) obtained through embryo rescue.
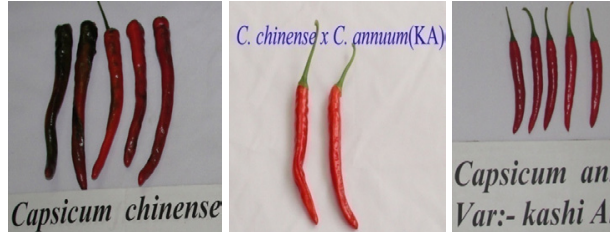

Capsicum annum

Var:- kashi Anmol

Plate 5: Fruits of parents and the hybrid.
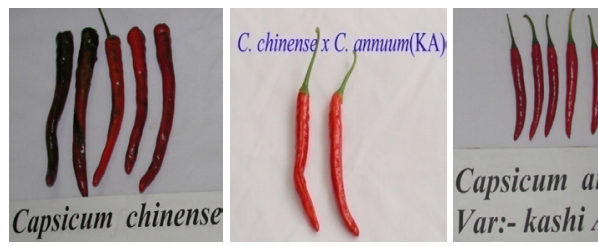

Capsicum annum

Var:- kashi Anmol

Plate 6: Fruits of parents and the hybrid. 
of the female band. The reproducibility of the pattern was verified: the primers that generated bands specific to the male parent were repeated at least two more times with the male, the female and the hybrid. Those primers giving the same pattern in the two replicates were chosen and were thereafter called RAPD markers. The rest were discarded. It was found that five primers were useful in determining the two hybrids. The efficiency to find a RAPD marker useful for hybrid determination was about $8 \%$. This value is similar to that found for tomato hybrids, another Solanaceous species, in which 13 primers showed good polymorphism between parents out of 160 primers tested [25] and the value also was similar to that found for hybrid seed purity analysis in which 53 primers showed good polymorphism between parents out of 100 primers tested [26]. In our study, these primers (8) generated 10 RAPD markers (Table 4). Six primers (OPE-02, OPG-19, OPP-08, OPV-12, OPZ-04 and OPZ$06)$ gave one marker and the other two (OPQ-07, OPV-06) showed two and three useful bands, respectively. On the other hand, two of the primers (OPV-12, OPZ-4) were good to confirm the hybridity. In total, the number of RAPD markers useful for checking hybridity of the two Capsicum embryo rescued hybrids ranged from zero (OPQ-7) to four (OPV-12)

The development of improved cultivars through hybridization has made a major contribution to increased productivity and quality of plants in different crop plants. Hybridization of genetically different parents is followed for hybrid cultivar development and molecular marker techniques are often used for fastening plant improvement [27]. One of the problems faced today by the breeders is the difficulty in identifying true hybrids from the crossed progenies before planting. Traditional method of hybrid identification based on morphological characters is influenced by environmental factors and lacks the resolving power to identify hybrids at juvenile stage, which makes it necessary to grow the plants up to maturity to confirm hybridity. Molecular markers used to detect DNA polymorphism are the most direct answer to it. Molecular analysis of genomes can be made with RAPD approach, where PCR allows exploration of large genomic portions.

Out of the 35 decamer primers used in RAPD analysis, 13 primers, viz., OPE-01, OPE-02, OPE-05, OPE-08, OPE-11, OPE-13, OPE16, OPE-17, OPE-18, OPE-19, OPE-20 and OPC-16 yielded the best amplification products [28]. Amplified products were scored on the basis of presence or absence of bands. RAPD banding pattern among parents and their hybrid population was compared to assess hybridity at the DNA level. Non-parental bands observed in some progenies might have resulted from DNA recombination or mutation. Chromosomal crossing-over during meiosis may have resulted in the loss of priming sites and thus markers are present in parents but not in offspring.

Black pepper being heterozygous and propagated through cuttings, segregation of characters can be expected in the hybrids progenies, which makes the bands from parents to be absent in hybrids. RAPD marker technique has potential application in the identification, registration and protection of pepper accessions. It will also help in screening of duplicates, assessing genetic diversity and monitoring the genetic stability of conserved germplasm, which has shown successful results in genus Piper.

Black pepper being heterozygous, markers diagnostic of each male parent is to be determined for each cross. Confirmation of hybrid nature of seedlings at the juvenile stage by screening with RAPD markers would be practical and of economic significance in a perennial crop like black pepper. It will enable elimination of all doubtful seedlings and can save labor, space and cost. RAPD can also be applied to broad array of cultivars and wild accessions for precise determination of genetic diversity within genus Capsicum.

Interspecific hybridization is essential to introgress resistance genes from Capsicum baccatum, a related species of cultivated pepper (C. annuum), since reliable genetic resources resistant to anthracnose have recently been identified within the C. baccatum germplasm but unfortunately in our case the seeds did not germinate.

To overcome post-fertilization barriers we studied the regeneration potential by taking immature crossed embryos as explants and succeeded in getting plantlets. We could confirm the hybridity by morphological and RAPD markers. One can study further by screening for the genes for resistance to diseases, etc. and make use of these hybrids for crossing programs and develop high yielding, disease resistant varieties.

\section{Confirmation of hybridity by morphological and molecular markers}

\begin{tabular}{|c|c|c|c|c|}
\hline SI. No. & Primer Code & $\begin{array}{c}\text { Total number } \\
\text { of bands }\end{array}$ & $\begin{array}{c}\text { Number of } \\
\text { polymorphic } \\
\text { bands }\end{array}$ & $\begin{array}{c}\text { (Polymorphic bands/ } \\
\text { Total bands)x100 }\end{array}$ \\
\hline 1 & OPE-2 & 7 & 4 & 57.14 \\
\hline 2 & OPG-19 & 5 & 2 & 40.00 \\
\hline 3 & OPP-8 & 5 & 1 & 20.00 \\
\hline 4 & OPQ-7 & 7 & 0 & 00.00 \\
\hline 5 & OPV-12 & 9 & 4 & 44.44 \\
\hline 6 & OPV-6 & 5 & 0 & 00.00 \\
\hline 7 & OPZ-4 & 6 & 2 & 33.33 \\
\hline 8 & OPZ-6 & 9 & 3 & 33.33 \\
\hline Total & & $\mathbf{5 3}$ & $\mathbf{1 6}$ & $\mathbf{2 2 8 . 2 4}$ \\
\hline Average & & $\mathbf{6 . 6 2}$ & $\mathbf{2}$ & $\mathbf{3 0 . 2 1}$ \\
\hline
\end{tabular}

Table 4: Total number of RAPD loci detected using 8 RAPD primers.

\section{Conclusion}

There were little differences in the average pollen viability among the species but showed huge differences in fruit set in reciprocal crosses. On selfing there was more pollen germination percentage compared to the crosses. Pollen germination had significant positive correlation with fruit set. Fruit set was high on selfing as compared to reciprocal crosses. Maximum fruit set was recorded on selfing of C. annuum, variety Pusa jwala (47 per cent). Both the species (C. frutescens and C. chinense) responded to embryo germination by MS+Yeast extract+casein hydrolysate $+\mathrm{GA}_{3}$ at $0.5 \mathrm{mg} / \mathrm{l}+\mathrm{NAA}$ at $0.05 \mathrm{mg} / \mathrm{l}$. NAA $(0.025 \mathrm{mg} / \mathrm{l}$ and $0.10 \mathrm{mg} / \mathrm{l}$ ) showed poor percent of embryo germination. Average number of plantlets was from the medium supplemented with $0.5 \mathrm{mg} / \mathrm{l}$ $\mathrm{GA}_{3}$ and NAA $0.05 \mathrm{mg} / \mathrm{l}$. Primers which amplified bands in the putative hybrids and were specific to the male parent confirmed the hybridity.

\section{Acknowledgments}

The authors would like to acknowledge funding received from College of PG Studies, Central Agricultural University (CAU), Imphal, Manipur for conducting the experiments. Mr. C. Debbarama was supported by funding from State Agricultural Department, Tripura. This work is part of MSc. Thesis.

\section{References}

1. Hore DK, Nagachan SV, Mishra A, Kadirvel G, Das A et al. (2010) Important plant genetic resources of North Eastern India: their sustainable utilization and conservation. In: Conservation of Natural Resources for Sustainable Hil Agriculture. ICAR Res pp: 85-92. Complex for NEHR, Umiam, Meghalaya.

2. Stebbins GL (1950) Variation and evolution in plants. Columbia Univ. Press, New York.

3. Srivastava M, Eidelman O, Torosyan Y, Jozwik C, Mannon RB, et al. (2011) 
Citation: Debbarama C, Khanna VK, Tyagi W, Rai M, Meetei NT (2013) Wide Hybridization and Embryo-Rescue for Crop Improvement in Capsicum. Agrotechnol S11:003. doi:10.4172/2168-9881.S11-003

Elevated expression levels of ANXA11, integrins $\hat{i}^{2} 3$ and $\hat{I} \pm 3$, and TNF-ît contribute to a candidate proteomic signature in urine for kidney allograft rejection. Proteomics Clin Appl 5: 311-321.

4. Shoemaker JS (1955) Small fruit culture. 3rd edn. Mc Graw- Hill, London.

5. Pae D, Cho M, Jung S (1995) Breeding for resistance in chilli pepper. NHRI Annual Report Pp 19-28.

6. Caranta C, Pflieger S, Lefebvre V, Daubèze AM, Thabuis A, et al. (2002) QTLs involved in the restriction of cucumber mosaic virus (CMV) long-distance movement in pepper. Theor Appl Genet 104: 586-591.

7. Dumas C, Gaude T (1981) Stigma- pollen recognition: a new look. In : Int Symp Adv Plant cytoembryology, Acta Soc Bot Pol 50: 235-247.

8. Clarke A, Gleeson P, Harrison S, Knox RB (1979) Pollen-stigma interactions: Identification and characterization of surface components with recognition potential. Proc Natl Acad Sci U S A 76: 3358-3362.

9. Heslop-Harrison J (1978) Recognition and response in the pollen-stigma interaction. Symp Soc Exp Biol 32: 121-138.

10. Heslop HJ (1979) Aspects of the structure, cytochemistry and germination of the pollen of rye (Secale cereale L.) Adv Bot 44: 47.

11. Heslop HJ, Heslop HY (1981) The pollen-stigma interaction in the grasses. Acta Botanica Neerlandica 30: 289-307.

12. AVRDC (1986) AVRDC adds pepper as new principal crop. Centre point 5: 1-3

13. Erickson AN, MarkhartAH (1999) Mechanisms of fruit set reduction in Capsicum annuum at high temperatures. American Society of Plant Biologists.

14. Kodali S, Khanna VK (1994) Standardization of the best timing of growth hormone application in wheat-barley crosses to increase seed set. Cer Res Comm 22: 309-312.

15. Raghavan V (1976) Experimental Embryogenesis in Vascular Plants. New York Academic Press.

16. Hossain MA, Minami M, Nemoto K (2003) Immature Embryo Culture and Interspecific Hybridization between Capsicum annuum L. and C. frutescens L. via Embryo Rescue. Japanese Journal of Tropical Agriculture 47: 9-16.
17. Fienup DM, Hamelin J, Reyes-Giordano K, Falcomata TS (2011) College-leve instruction: derived relations and programmed instruction. J Appl Behav Anal 44: 413-416.

18. Imanichi S, Watanabe Y, Hiura, I (1985) A simple and efficient method for the interspecific hybridization between Lycopersicon esculentum and $\mathrm{L}$. peruvianum. J. Yamagata. Agr For Soc 42: 13-15.

19. Thomas BR, Pratt D (1981). Efficient hybridization between L. esculentum and L. peruvianum via embryo callus. Theor Appl Genet 59: 215-219.

20. Kuriyama T, Kuniyasu K, Mochizuki H (1971) Studies on the breeding of disease- resistant tomato by interspecific hybridization. Influence of the environment and crossing factors on the frequency of interspecific hybrids. Bul Hort Res Station 10: 51-90

21. Yamakawa K (1971) Effect of chronic gamma radiation on hybridization between Lycopoersicon esculentum and L. peruvianum. Gamma Field Symposia 10: 11-30

22. Kuriyama T, Mochizuki $H$ (1971) Studies on the breeding of disease- resistan tomato by interspecific hybridization. I Fertility and disease resistance of the progenies of interspecific hybridization. Bull Hort Res Station 11: 33-60.

23. Poysa V (1990) The development of bridge lines for interspecific gene transfer between Lycopersicon esculentum and L. peruvianum. Theor Appl Genet 79 : 187-192.

24. Hogenboom NG (1972) Breaking breeding barriers in Lycopersicon. The genus Lycopersicon, its breeding barriers and the importance of breaking these barriers. Euphytica 21: 221-227.

25. Paran I, Aftergoot E, Shifriss C (1998) Variation in Capsicum annuum revealed by RAPD and AFLP markers. Euphytica 99: 167-173.

26. Ballester MJ, Vicente, MC (1998) Determination of F1 hybrid seed purity in pepper using PCR-based markers. Euphytica 103: 223-226.

27. Winter P, Kahl G (1995) Molecular marker technologies for plant improvement. World J Microbiol and Biotech 11: 438-448.

28. George KJ, Ganga G, Varma RS, Sasikumar B, Saji KV (2005) Identification of hybrids in black pepper (Piper nigrum L.) using male parent specific RAPD markers. Current Science 88: 216-218. 